\title{
Correction to: Spatial pattern of the effects of human activities on the land surface of China and their spatial relationship with the natural environment
}

\author{
Shuling $\mathrm{Hu}^{1,2} \cdot{\text { Bin } \mathrm{Yu}^{1}}^{1}$. Shen $\mathrm{Luo}^{1} \cdot$ Rongrong Zhuo ${ }^{1}$
}

Published online: 25 October 2021

(c) Springer Nature B.V. 2021

\section{Correction to: Environment, Development and Sustainability https://doi.org/10.1007/s10668-021-01871-6}

In this article, the statement in the Funding information section was incorrectly given, and it should be read as "The research was supported by the National Natural Science Foundation of China (Grant No.41671179)".

The original version of the article has been corrected.

Publisher's Note Springer Nature remains neutral with regard to jurisdictional claims in published maps and institutional affiliations.

The original article can be found online at https://doi.org/10.1007/s10668-021-01871-6.

Bin Yu

yubin@mail.ccnu.edu.cn

1 Key Laboratory of Hubei Province, Analysis and Simulation of Geographic Process, Central China Normal University, Wuhan 430079, China

2 College of Tourism and Culture Industry, Guizhou University, Guiyang 550025, China 